\section{Earth Observation for Humanitarian Assistance}

Gl_Forum 2017, Issue 1

Page: 157 - 165

Full Paper

Corresponding Author:

stefan.lang@sbg.ac.at

DOI: 10.1553/giscience2017_01_s157

\author{
Stefan Lang ${ }^{1}$, Elisabeth Schoepfer ${ }^{2}$, Peter Zeil ${ }^{3}$ and Barbara Riedler ${ }^{1}$ \\ 'Department of Geoinformatics Z_GIS, University of Salzburg, Austria \\ ${ }^{2}$ German Aerospace Center (DLR), German Remote Sensing Data Center (DFD), \\ Oberpfaffenhofen, Germany \\ 35patial Services GmbH, Salzburg, Austria
}

\begin{abstract}
Fast and efficient humanitarian assistance delivered to refugees or internally displaced persons requiresup-to-date reliable information about the situation on-site and the local/regional context. The usage of Earth observation data (acquired from space, aerial and ground platforms) for emergency and crisis mapping has greatly increased during recent years. This paper presents a broad overview of recent trends and achievements in this domain, ranging from satellite-based emergency mapping in the Copernicus domain and related initiatives, to crowd-sourced geospatial information and mapping NGOs, and a dedicated Earth observation-based single-user information service. Examples of best practice presented at a workshop complement the discussion of this wide range of activities for geo-humanitarian action.
\end{abstract}

\title{
Keywords:
}

Humanitarian action, refugee crisis, emergency, mapping, satellite, Copernicus

\section{A refugee crisisrequireseffective information updates}

Complex emergencies arising from armed conflicts, protracted crises and natural disasters have caused unprecedented population displacements, with an estimated number exceeding 65 million in 2015 (UNHCR). Efficient humanitarian assistance delivered to refugees or IDPs (internally displaced persons, as the significantly larger share of displaced people)requiresreliable up-to-date information about the situation on the ground and the local/regional context. This applies to mission planning in the immediate emergency phase as well assafeguarding care and maintenance in the longer term, thereby concerning not only the ever-changing population figuresbut alsothe supply of natural resources, including groundwater reservoirs. The collection of in-situdata to achieve an accurate picture is usually limited in terms of both time and access. 


\section{Earth observation to support emergency response and relief}

Geospatialand Earth observation (EO)technologies have become increasingly popular in the humanitarian community (Langet al., 2015). New technological advances accompany the strong need for effective tools. With respect to imaging, a large variety of optical as well as radar sensor types, including UAVs, provide a wide range of spatial, temporal and spectral resolutions. Turning the data from these sources into relevant geospatial information products for humanitarian actors remainsa challenge. In the domain of mainly natural disaster response, satellite-based emergencymapping (SEM)has reached a mature operational stageduring the last decade. The applications of satellite imagery as well as value-added products such as maps and vector datasets range from risk reduction and preparedness, to post-disaster damage assessment andrecovery.

\section{Satellite-based emergency mapping (SEM) mechanisms}

Various SEMmechanisms have become well established, providing satellite imagery and value-added products, and operating at different levels, from the national to the international. Table 1 provides a selection of SEM mechanisms, which are described in more detail below.

Table 1: Overview of operational SEM mechanisms

\begin{tabular}{|l|l|}
\hline $\begin{array}{l}\text { International Charter Space and Major Disasters (The } \\
\text { Charter) }\end{array}$ & $\begin{array}{l}\text { Global network of public satellite-operating } \\
\text { agencies, providing imagery and SEM services to } \\
\text { authorized users on a best-effort basis. Operational } \\
\text { since 2000. }\end{array}$ \\
\hline $\begin{array}{l}\text { European Copernicus Emergency Management } \\
\text { Service (CEMS) }\end{array}$ & $\begin{array}{l}\text { SEM service fully funded and implemented by the } \\
\text { European Commission. Mapping products are } \\
\text { generally provided under full and open access. } \\
\text { Operational since 2012. }\end{array}$ \\
\hline United Nations (UNITAR/UNOSAT) & $\begin{array}{l}\text { Project-based SEM service, mainly within the UN. } \\
\text { Operational since 2003. }\end{array}$ \\
\hline Sentinel Asia (SA) & $\begin{array}{l}\text { Initiative in the Asia-Pacific region; a voluntary } \\
\text { collaboration between regional space agencies and } \\
\text { disaster management institutions. Operational since } \\
2007 .\end{array}$ \\
\hline National Disaster Reduction Centre of China (NDRCC) & $\begin{array}{l}\text { Provides domestic SEM services for major disasters. } \\
\text { Operational since 2005. }\end{array}$ \\
\hline
\end{tabular}

The International Charter Space and Major Disasters (referred to as ${ }^{\circ}$ The Charter'),thanks to its global scope and its recent universal access efforts, is themost widely active and fully international SEM mechanism. In North America, the Charter is the only SEM mechanism used to complement domestic capacities. In South America, Africa, Europe and Asia, the SEM activities of the Charter are increasingly complemented by other mechanisms. For Europe, the CopernicusEmergency Management Service (CEMS) plays an increasingly important role, resulting in a substantial decrease of Charter activations over Europein the pastfive years. In Asia, Sentinel Asia(SA) activities have a strong prevalence, 
accompanied by the Charter and UNOSATmapping efforts. UNOSAT also plays a major role in Africa, the Near East, Central America, theCaribbean and South America. For China, the National Disaster Reduction Centre (NDRCC) plays the most important role, with the Chartercomplementing NDRCC capacities (Voigt etal,, 2016).In promoting cooperation between space agencies and space system operators in the use of space facilities as a contribution to the management of crises arising from natural or technological disasters, the Charterseeks to pursue the objectives (1) to supply critical data during periods of crisis for the management and anticipation of crises; (2) to support emergency assistance, reconstruction, as well as subsequent operations.

Once activated, the Charter provides satellite data. The SEM services are delivered by selected value-adders which are funded by the respective national governments (Mahmood et al., 2002;Bessis et al., 2004).

The Copernicus Emergency Management Service (CEMS)has beenin operation since April 2012. The service provides maps and analyses based on satellite imagery (before, during or after a crisis), as well as early warning services for flood and fire risks. Through these services, it supports crisis managers, civil protection authorities and humanitarian aid actors dealing with natural disasters, man-made emergency situations and humanitarian crises, as well as those involved in recovery, disaster risk reduction and preparedness activities. As an EU service, the CEMS's first priority is responding to EU needs and interests, whether within the EU or abroad.The CEMS comes under the overall political coordination and budgetary management of the European Commission's Directorate-General for Internal Market, Industry, Entrepreneurship and SMEs (DG GROW), and is operated through the 24/7/365 Emergency Response Coordination Centre (ERCC) at the Directorate-General for Humanitarian Aid and Civil Protection (DG ECHO). The Joint Research Centre (DG JRC) is in charge of technical support and contract management. The service, which is free of charge, must be activated by an Authorized User(European Parliament and Council, 2014; European Commission,DG GROW et al., 2015).

Operational since 2003, UNITAR/UNOSAT Rapid Mapping provides satellite image analysis during humanitarian emergencies, both natural disasters and conflictsituations. With a $24 / 7$, year-round availability to process requests, a team of experienced analysts ensure timely deliveryof maps derived from satellite imagery, reports and GIS-ready data. UNOSAT benefits from a variety of sources for its satellite imagery: free and open-source, commercial vendors, International Charter Space and Major Disasters (natural and technological disasters only), in-kind donations.The service is free of charge for UN sister agencies and humanitarian entities operating in line with UN policies. UNOSAT's services can be requested by UN offices and agencies, government agencies, the Red Cross and Red Crescent (ICRC and IFRC), international and regional organizations, and humanitarian nongovernmental organizations (NGOs). Thanks to predictable donor funding coming from Norway, Sweden and Denmark, UNOSAT has been able to meet all of these demands since 2007 (UNITAR/UNOSAT, 2017).

Sentinel Asia (SA) was established in 2005 asacollaboration between space agencies and disaster management agencies under the Asia-Pacific Regional Space Agency Forum (APRSAF) initiative, applying remote sensing and Web-GIS technology to assist disaster 
management in the Asia-Pacific region. A step-by-step approach for the implementation of SA was adopted (Kaku\& Held, 2013). InStep1 (2006-2007), implementation of an initial backbone SA data-dissemination system was established, as a pilot project to demonstrate the value and impact of technology using standard internet dissemination systems. Subsequently, Step2 (2008-2012) concentrated on the expansion of the system with additional member countries and their agencies, and the expansion of the dissemination backbone with new satellite communication systems, such as the Wideband Internetworking Engineering Test and Demonstration Satellite (WINDS) of the Japanese Space Agency JAXA, and additional nodes and satellite data sources. The final implementation step, Step3, launched in 2013, oversees consolidation activities to establish a comprehensive, operational and enduring disaster management support system in the Asia-Pacific region, focusing in particular on:

- Regional cooperation to promote utilization of Sentinel Asia by end-users and make success stories, and its expansion to other countries;

- Utilizing many and varied satellites, such as Earth observation, communication and navigation satellites;

- Better covering the entire disaster management cycle: the mitigation/preparedness phase and recovery phase, as well as the response phase;

- Cooperation with other activities concerningdisaster management.

\section{Advantages and disadvantages of SEM for humanitarian support}

Without doubt, humanitarian actors make the best use of satellite-based information products today (Fürederetal., 2015; Langet al.,2015) to support the effectiveness - and in the long termthe efficiency - of their operations. Access to commercial very-high resolution imagery paved the way for almost unrestricted use within the workflow of humanitarian organizations (predominantly NGOs). 'Almost unrestricted', however, needs some consideration. One of the most crucial prerequisites for the unhindered operation of humanitarian organizations is their independence,especially for NGOs. Using commercial satellite data therefore leads to the following questions/considerations:

- Who will use the derived information and for what purposes? In the case of information products beingshared between several actors (e.g. UN, NGOs, national organizations), the intended uses may be conflicting or at least different, which could endanger the 'neutrality' of some of the actors.

- Conflict of interest - military versus human security.In crisis situations, the same information product may be used by the military as well as by actors in the humanitarian sectorto provide protection for people in an armed conflict. That further leads to:

- The sensitivity issue - whom to protect? Sensitivity applies to the protection of (a) rights (such as privacy, human rights) and(b) interests (such as security, as defined by military operations). There have been cases where even the data were considered 
sensitive, leading either to their dissemination being restricted or to the spatial resolution being degraded.

- Full and open access - dilemma: the use of commercial very-high resolution satellite data by those who do not control itsacquisition cannot be considered fully open. Commercial satellite providers operate under the legal conditions of national governments, which reserve the right to restrict the data dissemination iftheir interests becomeendangered.

Even though data are available, the derived information product may be sensitive - if it falls into the 'wrong' hands. For humanitarian NGOs, the best option would be for them to rely on an information service of their own, dedicated to the particular tasks that the organization performs. One such dedicated service that takes into account the organization's specific constellation of needs and what is offered to fulfil those is illustrated in section 3.2.

\section{Humanitarian mapping service}

\section{The wider humanitarian mapping community}

Alongside the established SEM mechanisms, new organizations associated with the humanitarian mapping community have emerged over the last few years. Crowd-mapping initiatives are producing geospatial data on geographical features (e.g. information layers on roads, buildings etc.) considered critical for the delivery ofaid in humanitarian operations or for awareness about the situation in general.Under the slogan 'Mapping Our World Together',the Humanitarian OpenStreetMap Team (HOT)1 has as its mission to create maps for humanitarian response, adhering strictly to the principles of open source and open data sharing. It is based on the OSM network, which forms the largest crowdsourcing community globally. HOT also enables collaborative mapping between different actors - governmental, organizational and the public at large. In addition to the actual mapping of areas not mapped in detail so far, it also supports deployment missions to the field.

Other such 'grassroot' initiatives are MissingMaps, MapGive,YouthMapper or UAViators, the Humanitarian Unmanned Aerial Vehicle (UAV) network. Recently, based on the principle of hackathons, i.e. to physically connect skilled and eager volunteers in a creative and outcome-oriented environment,mapathonshave emerged, which stimulate joint work on map production and digitalization. There have been a series of mapathons in the humanitarian sector, launched jointly by the Austrian Red Cross and the Austrian section of Médicins Sans Frontières (MSF, Doctors without Borders), with a session taking place in the context of the EO4Hum workshop.

This emerging community of humanitarian Volunteered Geographic Information (VGI) is complemented by dedicated NGOs that provide professional-level mapping services, the aim of which is rapid, on-site mapping, as well as gathering of other information to support decision-making in humanitarian actions.Here we mention MapAction and CartONG, with activity fields in natural disaster response (e.g. earthquake in Nepal, hurricane in Haiti, etc.),

\footnotetext{
${ }^{1}$ www.hotosm.org
} 
conflict areas and refugee camp mapping, as well as epidemic risks, such as the Ebola crisis in 2014.

\section{A success story:an EO-based information service supporting humanitarian assistance for MSF}

An EO-based information service established at Z_GIS, University of Salzburg2, provides dedicated geospatial information products in supportofhumanitarian operations. The products developed are delivered as tailor-made maps, online web services and advanced cartographic visualizations, utilized and validated by teams on the ground (Fürederet al. 2015). The information service was set up for,and collaboratively designed with,MSF, an independent, international humanitarian organization operating around the world. The service has been running operationally since 2012 and undergoes constant refinement at the product- and information-request levels. This may be considereda typical case for a 'singleuser' service, in particular in its original conceptualization.

Figure 1 shows one of the maps delivered to MSF regarding the statusof the Minawao refugee camp in Cameroon in March 2015. Based on the extraction of different dwelling types, various camp sectors and their specific internal arrangements can be mapped. This serves as a reference for ongoing monitoring activities of the camp and its surroundings.
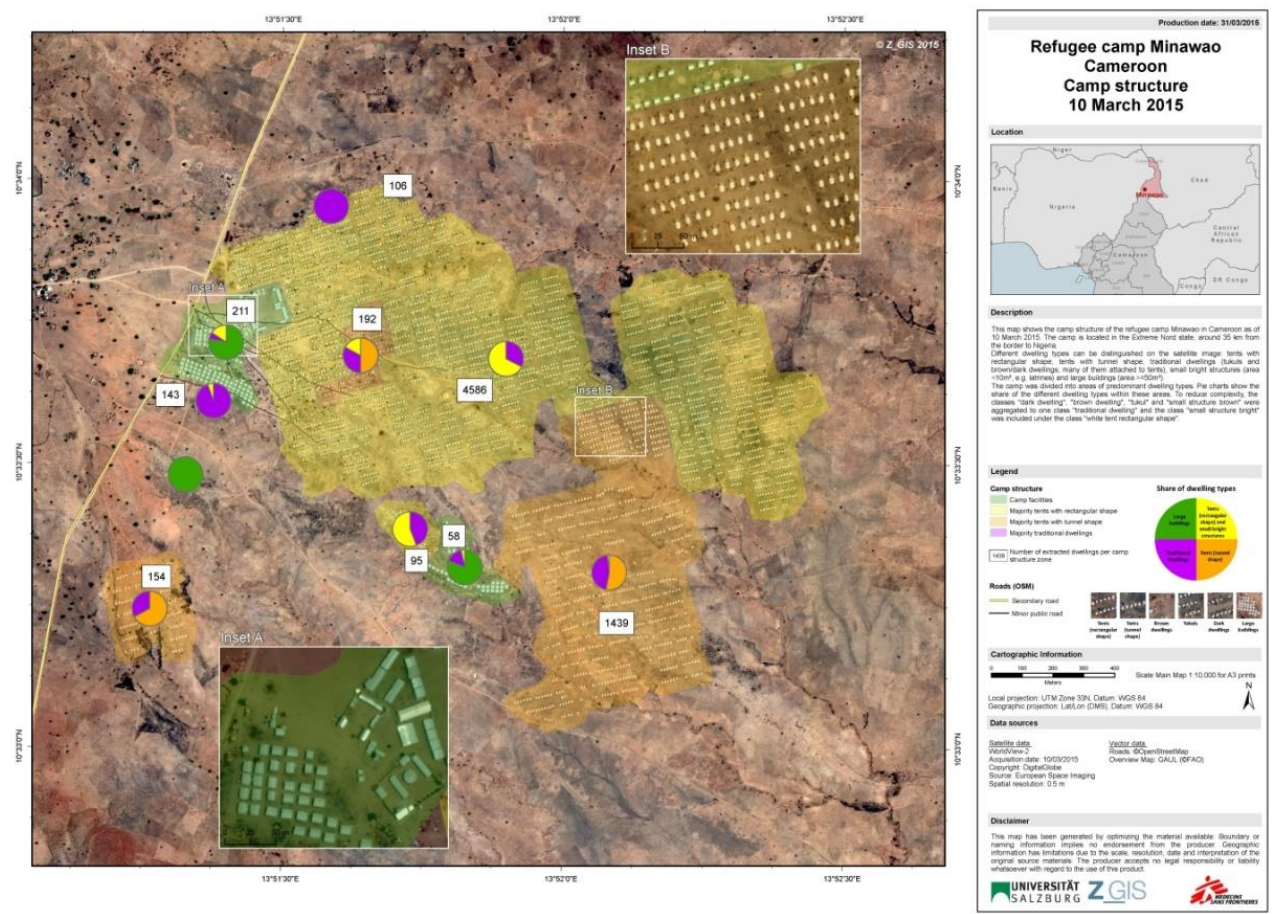

Figure 1: Zoning map of Minawao refugee camp in Cameroon, showing distribution and share of different dwelling types. () Credits Z_GIS, MSF.

${ }^{2}$ www.zgis.at/humanitarian-services 


\section{Special session EO4Hum}

\section{Scope of the workshop}

The special session Earth Observation for Humanitarian Assistance 3 focused on the potential of satellite data and geospatial technologies to support humanitarian assistance in crisis and disaster response. The contributions rangedfrom $\mathrm{R} \& \mathrm{D}$ and practical applications, to experiences in applying new methods, tools and technologies for dedicated geospatial information products in all phases of humanitarian crises.The topics called for covered:

- Monitoring and tracking displaced population

- Early-warning indicators for humanitarian crises

- Crowd mapping, humanitarian VGI

- UAVs and mobile devices

- Crisis monitoring (water supplies, infrastructure, natural resources)

- Assessment of mid- to long-term effects of humanitarian crises

- New EO data and their potential, including Copernicus Sentinels

- Links to the Copernicus Emergency Management Service (CEMS)

\section{Best practice example}

The contributions selected cover various application fields in the humanitarian domain, ranging from water management (Burrows et al., Riedler et al., Sudmanns et al., Toca et al.) to population monitoring of refugee/IDP camps (Braun \&Hochschild, Wendt et al.) and disaster preparedness and response (Lechner et al., Riedler et al., Sudmanns et al.). The use of different EO data sources, including radar data (Braun \&Hochschild, Lechner et al.), VHR satellite imagery (Lechner et al., Riedler et al.), and freely available satellite data from Sentinel (Lechner et al., Wendt et al.) and Landsat (Sudmanns et al.), with their specific advantages, challenges and limitations, are demonstrated and discussed. Finally, various innovative technical solutions, from intelligent querying systems (Sudmanns et al.) to automated early warning services (Lechner et al.) and integrated database environments for sharing data within the humanitarian community (Burrows et al., Schörghofer et al., Toca et al.), are presented.

In detail, Braun \&Hochschild discuss the potential and limitations of radar data, so far only rarely used in the humanitarian field, with illustrative examples for population monitoring, hydrology and the management of natural resources. Another novel data source is used by Wendt et al., who show the applicability of optical Sentinel imagery for the monitoring of refugee/IDP camps by automatic change assessments of large, regularly structured camps. They investigate the potential to extract camp extent and dwelling estimates from Sentinel-2 imagery and compare this potential to analysis based on VHR imagery. An automated preclassification of long time series of Landsat 8 images in combination with an intelligent query system (IQ) is used by Sudmanns et al. for the detection of temporal flood patterns and the

\footnotetext{
${ }^{3}$ EO4Hum workshop took place on July 4, 2017 during GI_Forum 2017
} 
extraction of flood-prone areas. Lechner et al. analyse the value of EO technology to strengthen disaster preparedness and management through developing pre-operational services tailored to the specific needs of the NGO SOS Children's Villages, providing automated EO-based fire and flood information as well as satellite-based emergency mapping. Using well-established GIS methods to support the rehabilitation of water supply infrastructure by the Nepal Red Cross Society after the earthquakes in 2015, Riedler et al. show the potential, in the context of post-disaster management, of an integrated assessment that covers precise height information, population estimation, land use and the incorporation of national standards. Toca et al. point out the importance of the use of remote sensing and GIS-derived products integrated in an updated and well-structured database for the management of water resources and supply, especially in drought- and conflict-stricken regions where the International Committee of the Red Cross (ICRC) works regularly and information need is high. The importance of such updated databases is also emphasized by Burrows et al., who demonstrate an open-access online database solution (waterdatarocks) designed by the NGO Ground Water Relief to collect and share groundwater-related data within the humanitarian community in order to support field work, especially in countries where groundwater data is otherwise not accessible. Designed not solely for water-related issues but a broad field of applications in the humanitarian sector, the OGC-conform, opensource collaborative mapping platform (CMap) presented by Schörghofer et al. provides, in addition to data sharing, a dynamic and integrated mapping environment with WebGIS functionalities of dynamic visualizations.

\section{$5 \quad$ Conclusion and outlook}

The usage of EO data (be they aerial or acquired from space or ground platforms) for emergency and crisis mapping has increased massively during recent years. Because of the rising number of remote sensing systems and increasing image accessibility, as well as increased awareness within the humanitarian community of the benefit of using such technologies, we can expect the current trend of rapid proliferation to continue.One challenge isthe integration of massive (or even big?) data being produced by volunteers all over the world and the growing amount of in-situ data collected by UAVs. In addition, we are witnessing the emergence and use of new technologies, such as 'human sensors' and their use (also referred to as 'collective sensing'), based on the distribution via social media activities and mobile phonesignals. Human sensors are increasingly used to track and analyse the movement patterns of people, giving rise to new issues of ethics and privacy, and discussion of the potential benefits of such tracking techniques. This clearly takes us beyondthe snapshot-likeobservationsprovided byremote sensing imageryand opens new challenges, both in technical and in ethical terms. 


\section{Acknowledgements}

This work has been co-funded by the Austrian Research Promotion Agency (FFG) under the Austrian Space Application Programme (ASAP) within the project EO4HumEn+ (contract no: 854041).

We acknowledge the time and effort spent by anonymous reviewers and language checking, which helped improve the manuscript.

\section{References}

Bessis,J. L., Bequignon, J.,\&Mahmood, A. (2004).The International Charter "Space and Major Disasters" initiative.Acta Astronaut. 54, 183-190. doi:10.1016/S0094-5765(02)00297-7

European Commission DG GROW, DG ECHO\& DG JRC(2015). Copernicus Emergency Management Service Mapping Manual of Operational Procedures.Version 1.1. Retrieved fromhttp://emergency.copernicus.eu/mapping/sites/default/files/files/EMS_Mapping_Manual_ of_Procedures_v1_1.pdf

European Parliament and Council (2014). Regulation (EU) No 377/2014 of the European Parliament and of the Council of the 3 April 2014 establishing the Copernicus Programme and repealing Regulation (EU) No 911/2010 (2014). Retrieved from http://copernicus.eu/sites/default/files/library/Regulation_377_2014_Copernicus_3April2014.p df

Füreder, P., Lang, S., Hagenlocher, M., Tiede, D., Wendt, L.,\&Rogenhofer, E., 2015. Earth observation and GIS to support humanitarian operations in refugee/IDP camps.In: Proceedings of the ISCRAM 2015 Conference, Kristiansand, May 24-27 2015. Retrieved fromhttp://iscram2015.uia.no/wp-content/uploads/2015/05/5-4.pdf

Kaku, K.,\&Held, A. (2013).Sentinel Asia: A Space-based Disaster Management Support System in the Asia-Pacific Region. Int. J. Disast. Risk Reduct. 6, 1-17. doi:10.1016/j.ijdrr.2013.08.004

Lang, S., Füreder, P. Kranz, O., Card, B., Roberts, S.,\& Papp, A.(2015). Humanitarian emergencies: causes, traits and impacts as observed by remote sensing. P. Thenkabail (ed.) Remote Sensing Handbook, New York: Taylor and Francis, 483-512.

Mahmood, A., Bessis, J. L., Bequignon, J., Lauritson, L.,\&Venkatachary, K.V. (2002).An Overview of the International Charter 'Space and Major Disasters'. Int. Geosci. Remote Sens. 2, 771-773. doi:IGARSS.2002.1025681.

UNITAR/UNOSAT (2017).UNITAR's Operational Satellite Applications Programme - UNOSAT. Retrieved fromhttps://unitar.org/unosat/

Voigt, S., Giulio-Tonolo, F., Lyons, J., Kučera, J., Jones, B., Schneiderhan, T., Platzeck, G., Kaku, K., Hazarika, M.K., Czaran, L., Li, S., Pedersen, W., James, G.K., Proy, C., Muthike, D. M., Bequignon, J.,\&Guha-Sapir, D., 2016. Global trends in satellite-based emergency mapping. Science, 353 (6296), 247-252. doi:10.1126/science.aad8728 